\title{
COMMENTARY
}

\section{Preserving spontaneous breathing during mechanical ventilatory support: an old yet fascinating story}

\author{
Enrico Calzia ${ }^{*}$ and Rolf Dembinski \\ See related research by Saddy et al., http://ccforum.com/content/17/5/R228
}

\begin{abstract}
Facilitation of early spontaneous breathing activity is the most important measure to shorten weaning and avoid ventilator-induced lung injury and diaphragmatic injury in mechanically ventilated patients. However, the optimal degree of spontaneous muscle activity and ventilator support remains to be determined. Furthermore, effectiveness in relation to the pathophysiology of respiratory failure is unclear. In this regard the experimental study by Saddy and colleagues reveals interesting insights into the pathophysiology of ventilator-induced injury. More important, their results raise important questions that should be evaluated in further studies.
\end{abstract}

In a recent issue of Critical Care, Saddy and colleagues [1] present an important article on the impact of partial ventilatory support on lung tissue inflammation and diaphragm dysfunction in mechanically ventilated rats. Their data reveal surprising results, in particular showing that the degree of diaphragmatic injury may depend not only on the amount of spontaneous respiratory activity preserved by applying specific settings of mechanical support, but also on the etiology of acute lung injury; that is, pulmonary versus extrapulmonary acute respiratory distress syndrome (ARDS). The present article reminds us that the question posed by Milic-Emili in a commentary published nearly 30 years ago as to whether weaning is an art or a science [2] is still valid, albeit a substantial body of available evidence now

\footnotetext{
* Correspondence: enrico.calzia@uni-ulm.de

${ }^{1}$ Ulm University, Department of Anesthesia, Section of Anesthesiological Pathophysiology and Process Development, Helmholtzstr. 8/1, 89081, Ulm, Germany

Full list of author information is available at the end of the article
}

clearly explains several pathophysiological details of respiratory muscle failure in ICU patients $[3,4]$.

Of course, the relevance of animal models in translational research may always be questioned. This is particularly the case for rodent models, as the validity of the inflammatory response in these species as a model for human diseases has been challenged very recently [5]. Furthermore, respiratory mechanics widely differs between humans and rodents, as suggested, for example, by the different physiological respiratory rates that are relatively higher in the latter species and may, therefore, influence gas transport and exchange [6]. Nevertheless, the present study has the major merits of, firstly, having included diaphragm function and morphology (a relevant topic that still deserves fundamental research), and, secondly, having quantified diaphragmatic activity under different experimental conditions by means of the pressure-time product. This variable is calculated by tracing the esophageal pressure and is therefore particularly challenging to measure in small animals, but it is close to clinical reality as it is fairly well accessible in humans and may therefore support translating experimental results into clinical conditions [7].

Taken together, the present data confirm, in principle, the well accepted notions that passive mechanical ventilation quickly damages the diaphragm [8] and promotes lung injury by atelectasis formation [9]. However, they also reveal that the impact of mechanical ventilation may be more difficult to explain, especially in extrapulmonary ARDS. In fact, under partial spontaneous breathing combined with low degree of ventilator support the authors observed an unexpected increase in diaphragmatic injury whereas atelectasis formation decreased comparable to pulmonary ARDS.

These fairly surprising results may remind us that the impact of mechanical ventilation on lung tissue and the diaphragm is still far from being completely understood 
and merit intensive study in the future. In particular, some effort should be spent reproducing in the experimental conditions factors that potentially influence the response to mechanical ventilation in clinical settings. For example, most ICU patients are affected by coexisting diseases, especially cardiovascular diseases, diabetes, and chronic obstructive pulmonary disease, which, independent of the acute condition, also influence the muscular and diaphragmatic function and may even accentuate the impact of mechanical ventilation.

Animal models mimicking conditions of co-existing chronic diseases should therefore be recommended to improve translation of experimental data into clinical situations and may be considered as the next step in studying the impact of mechanical ventilation and partial spontaneous breathing on diaphragm and lung tissue. Furthermore, most patients requiring mechanical ventilator support are affected by septic conditions leading to organ dysfunction and metabolic disorders. The utility of partial spontaneous breathing for maintaining diaphragmatic function has been well demonstrated in several experiments and nicely confirmed in the present study, but the effects of spontaneous breathing under septic conditions still need to be investigated. Finally, it is well known that not only restriction of passive movement but also muscular overload due to increased work of breathing may cause structural diaphragmatic damage that is characteristic for weaning failure. Thus, another important task of further studies is to find the perfect balance between diaphragmatic loading and unloading with regard to diaphragmatic and pulmonary function. In this context it will be interesting to see if modern spontaneous breathing modes may find their role in future concepts of lung and diaphragmatic protective ventilation strategies.

In summary, the present article improves our knowledge in a fundamental topic of critical care and should encourage us to further study the influence of mechanical ventilatory support on lung tissue and diaphragm function, which is likely to be an important key to improving patient outcome in the ICU.

\footnotetext{
Abbreviations

ARDS: Acute respiratory distress syndrome.

Competing interests

The authors declare that they have no competing interests.

Author details

${ }^{1}$ Ulm University, Department of Anesthesia, Section of Anesthesiological Pathophysiology and Process Development, Helmholtzstr. 8/1, 89081, Ulm, Germany. ${ }^{2}$ Klinikum Bremen Mitte, Department of Intensive Care Medicine and Emergency Medicine, St.Jürgen-Str. 1, 28177, Bremen, Germany.
}

Published: 19 Nov 2013

\section{References}

1. Saddy F, Moraes L, Santos LC, Oliveira GP, Cruz FF, Morales MM, Capelozzi VL, Gama De Abreu M, Garcia CSNB, Pelosi P, Rocco PRM: Biphasic positive airway pressure minimizes biological impact on lung tissue in mild acute lung injury independent of etiology. Crit Care 2013, 17:R228.

2. Milic-Emili J: Is weaning an art or a science? Am Rev Respir Dis 1986, 134:1107-1108.

3. Powers SK, Wiggs MP, Sollanek KJ, Smuder AJ: Ventilator-induced diaphragm dysfunction: cause and effect. Am J Physiol Regul Integr Comp Physiol 2013, 305:R464-R477.

4. Jaber S, Jung B, Matecki S, Petrof BJ: Clinical review: ventilator-induced diaphragmatic dysfunction - human studies confirm animal model findings! Crit Care 2011, 15:206.

5. Seok J, Warren HS, Cuenca AG, Mindrinos MN, Baker HV, Xu W, Richards DR, McDonald-Smith GP, Gao H, Hennessy L, Finnerty CC, López CM, Honari S, Moore EE, Minei JP, Cuschieri J, Bankey PE, Johnson JL, Sperry J, Nathens AB, Billiar TR, West MA, Jeschke MG, Klein MB, Gamelli RL, Gibran NS, Brownstein BH, Miller-Graziano C, Calvano SE, Mason PH, et al:: Genomic responses in mouse models poorly mimic human inflammatory diseases. Proc Natl Acad Sci U S A 2013, 110:3507-3512.

6. Tsujino I, Kawakami Y, Kaneko A: Comparative simulation of gas transport in airway models of rat, dog, and human. Inhal Toxicol 2005, 17:475-485.

7. Meade M, Guyatt G, Cook D, Griffith L, Sinuff T, Kergl C, Mancebo J, Esteban A, Epstein S: Predicting success in weaning from mechanical ventilation. Chest 2001, 120:400S-424S.

8. Levine S, Nguyen T, Taylor N, Friscia ME, Budak MT, Rothenberg P, Zhu J, Sachdeva R, Sonnad S, Kaiser LR, Rubinstein NA, Powers SK, Shrager JB: Rapid disuse atrophy of diaphragm fibers in mechanically ventilated humans. N Engl J Med 2008, 358:1327-1335.

9. Putensen C, Mutz NJ, Putensen-Himmer G, Zinserling J: Spontaneous breathing during ventilatory support improves ventilation-perfusion distributions in patients with acute respiratory distress syndrome. Am J Respir Crit Care Med 1999, 159:1241-1248.

\section{$10.1186 / \mathrm{cc} 13120$}

Cite this article as: Calzia and Dembinski: Preserving spontaneous breathing during mechanical ventilatory support: an old yet fascinating story. Critical Care 2013, 17:1013 